\title{
Dégradation de matières grasses protégées in situ chez la vache
}

\author{
C Bayourthe, M Vernay \\ École nationale supérieure agronomique, laboratoire d'Ingénierie agronomique, 145, avenue de Muret, \\ 31076 Toulouse Cedex, France
}

\begin{abstract}
Summary - In situ degradation of protected fat in the cow. Rumen degradability and intestinal disappearance of encapsulated fats (Prolip) and calcium soaps (Megalac) were determined using the in sacco technique. Compared with Megalac, fats associated with rumen by-pass protein had higher rumen degradability of both dry matter (44 vs $10 \%)$ and fatty acids (63 vs $15 \%)$. The in sacco intestinal disappearance of fats that escaped rumen digestion was significant: $77 \%$ for Prolip and $87 \%$ for Megalac.
\end{abstract}

Les matières grasses (MG) introduites en quantité importante dans la ration des ruminants dépriment la digestion des autres composants. Afin d'éviter de tels effets, il est possible d'utiliser des lipides protégés ou lipides «by-pass". L'objectif de notre étude a été d'estimer, in situ chez la vache, la dégradabilité ruminale et la digestibilité intestinale de 2 types de MG protégées.

Matériel et méthodes - Quatre vaches Holstein canulées (rumen, duodénum) ont reçu une ration composée de foin de ray-grass $(70 \%)$ et de tourteau de soja $(30 \%)$. Ont été testés : une émulsion d'acides gras dans une matrice protéique, le Prolip ${ }^{(k)}$ (Cofna, Tours, France) et des savons de calcium, le Mégalac ${ }^{(i)}$ (Volac France, Asnières). Le Mégalac contient $97 \%$ de MS et $85 \%$ d'extrait éthéré, les valeurs correspondantes pour le Prolip sont : 86 et $32 \%$; la teneur en matières azotées (MA) de ce dernier étant de $62 \%$. Pour les 2 produits utilisés, $88 \%$ des particules avaient une taille supérieure à $250 \mu$. Les mesures de dégradation dans le rumen ont été réalisées par la technique des sachets de nylon ( $7 \times 11 \mathrm{~cm}$; porosité $46 \mu$; $3 \mathrm{~g}$ de MS). Chaque série d'incubation comprenait 6 points de cinétique $(2,4,8,16,24,48 \mathrm{~h})$ à raison de 3 sachets/ temps de séjour/vache/aliment. Les résultats de dégradation ont été ajustés au modèle exponentiel décrit par Ørskov et McDonald (1979); les valeurs de dégradabilités (DTMS, DTMG, DTMA) ont été calculées en admettant un taux de sortie horaire des particules de 0,06. La fraction apparemment indigestible a été obtenue après un séjour ( $16 \mathrm{~h}$ ) dans le rumen de 7 minisachets ( $6 \times 6 \mathrm{~cm}$; porosité $46 \mu ; 1,5 \mathrm{~g}$ de MS)/ vache/aliment, attaque pepsique et transit dans l'intestin (Peyraud et al, 1988).

Résultats et discussion - Les coefficients des cinétiques de dégradation (MS, $M G, M A$ ) et les valeurs de DT sont présentés dans le tableau I; le mode de protection des MG a influencé la dégradation des composants. Le Mégalac est caractérisé par des valeurs de DTMS et de DTMG inférieures à celles du Prolip (10,3 vs 43,8 et 14,7 vs 63,2 , respectivement), ce qui va dans le sens des données bibliographiques. Après $20 \mathrm{~h}$ d'incubation in sacco dans le rumen de divers savons de calcium, Sklan (1989) obtient une faible disparition de MS (4 à 16\%); les valeurs de $\mathrm{pH}$ qui règnent dans le rumen ne favorisent pas la dissociation des savons de calcium (Sukhija et Palmquist, 1990). En effet, par rapport au Prolip, il apparaît que la moindre dégradation des MG du Mégalac est due à la très faible représentation de la fraction immédiatement soluble $a$ : 5,7 vs $52,9 \%$; la fraction plus lentement dégradable $b$ et la vitesse $c$ de dégradation de cette fraction n'étant pas différentes. Le Prolip est une émulsion 
d'acides gras et de farine de sang traitée à $110^{\circ} \mathrm{C}$, la résistance des protéines vis-àvis de l'attaque par les micro-organismes ruminaux est le facteur essentiel de cette protection. La valeur de DTMA obtenue pour le Prolip est supérieure à celle qui est donnée par Satter (1986) pour la farine de sang (47 vs $35 \%$ ); cet écart pouvant s'expliquer par la température de séchage du produit qui diffère $\left(140^{\circ} \mathrm{C}\right)$. Les valeurs de digestibilité totale des MG du Prolip $(91,4 \%)$ et du Mégalac $(89,2 \%)$ n'étant pas significativement différentes, le pourcentage de MG qui disparaît des sachets dans l'intestin est plus important pour le Mégalac (75 vs $28 \%$ de l'initial); il en est de même pour la digestibilité intestinale apparente des MG résiduelles ruminales : 87 vs $77 \%$. Ces valeurs élevées trouvent une explication dans la complète dissociation des savons de calcium en milieu duodénal acide (Sukhija et Palmquist, 1990), d'une part, et dans la bonne digestibilité intestinale des MA du Prolip $(88,8 \%)$, d'autre part.

Remerciements - Ce travail a été subventionné par la société Cofna (25, rue du Rempart, 37018 Tours Cedex, France).
Ørskov ER, McDonald I (1979) J Agric Sci (Camb) 92, 499-503

Peyraud JL, Genest-Rulquin C, Vérité R (1988) Reprod Nutr Dev 28, 129-130

Satter LD (1986) J Dairy Sci69, 2734-2749

Sklan D (1989) J Agric Sci (Camb) 112, 79-83

Sukhija PS, Palmquist DL (1990) J Dairy Sci 73, 1784-1787

Tableau I. Coefficients des cinétiques de dégradation et valeurs de dégradabilité théorique des matières sèche (MS), grasse (MG) et azotée (MA) dans le rumen pour le Prolip et le Mégalac.

\begin{tabular}{lccccc}
\hline $\begin{array}{l}\text { MG } \\
\text { protégées }\end{array}$ & $\begin{array}{c}a \\
(\%)\end{array}$ & $\begin{array}{c}b \\
(\%)\end{array}$ & $\begin{array}{c}c \\
\left(r^{-1}\right)\end{array}$ & $r^{2}$ & $\begin{array}{c}D T \\
(\%)\end{array}$ \\
\hline $\begin{array}{l}\text { Prolip } \\
\text { MS }\end{array}$ & 32,4 & 60,4 & 0,014 & 0,79 & 43,8 \\
$\quad$ MG & 52,9 & 37,9 & 0,022 & 0,63 & 63,2 \\
$\quad$ MA & 36,7 & 55,2 & 0,013 & 0,81 & 46,6 \\
Mégalac & & & & & \\
$\quad$ MS & 1,8 & 43,0 & 0,015 & 0,71 & 10,3 \\
MG & 5,7 & 41,0 & 0,017 & 0,64 & 14,7 \\
& & & & & \\
\hline
\end{tabular}

$a, b$ et $c$ : coefficients des equations de Orskov et McDonald (1979); $D T$ : dégradabilité théorique pour un taux de sortie horaire des particules de 0,$06 ; r^{2}$ : coefficient de détermination. 